\title{
Land use and cover change scenarios in the Mesoamerican Biological Corridor-Chiapas, México
}

Diana Ramírez-Mejía, Gabriela Cuevas, Paula Meli, Eduardo Mendoza

\section{Supplementary Information}

Table 1s. Extent and rates of change of the different land use and cover categories in the Mesoamerican Biological Corridor-Chiapas in the different periods evaluated.

\begin{tabular}{lrrrrrrrr} 
Land cover & \multicolumn{2}{c}{$\mathbf{1 9 9 3}$} & \multicolumn{2}{c}{$\mathbf{2 0 0 2}$} & \multicolumn{2}{c}{$\mathbf{2 0 0 7}$} & \multicolumn{2}{c}{ LUCC rates } \\
class & ha & \% & ha & $\%$ & ha & \% & $\begin{array}{r}\mathbf{1 9 9 3 - 2 0 0 2} \\
(\% / \text { year })\end{array}$ & $\begin{array}{r}\mathbf{2 0 0 2 - 2 0 0 7} \\
(\% / y e a r)\end{array}$ \\
\hline TroF & 837525 & 23.29 & 662500 & 18.42 & 626125 & 17.41 & -2.57 & -0.80 \\
TroSF & 707500 & 19.68 & 772850 & 21.49 & 741550 & 20.62 & 0.99 & -0.59 \\
TemF & 626425 & 17.42 & 421800 & 11.73 & 360200 & 10.02 & -4.30 & -2.23 \\
TemSF & 355225 & 9.88 & 520850 & 14.48 & 560125 & 15.58 & 4.34 & 1.04 \\
ALF & 1003550 & 27.91 & 1151475 & 32.02 & 1243750 & 34.59 & 1.54 & 1.11 \\
OC & 65675 & 1.83 & 66425 & 1.85 & 64150 & 1.78 & 0.13 & -0.50 \\
Total & 3595900 & 100 & 3595900 & 100 & 3595900 & 100 & & \\
\hline
\end{tabular}
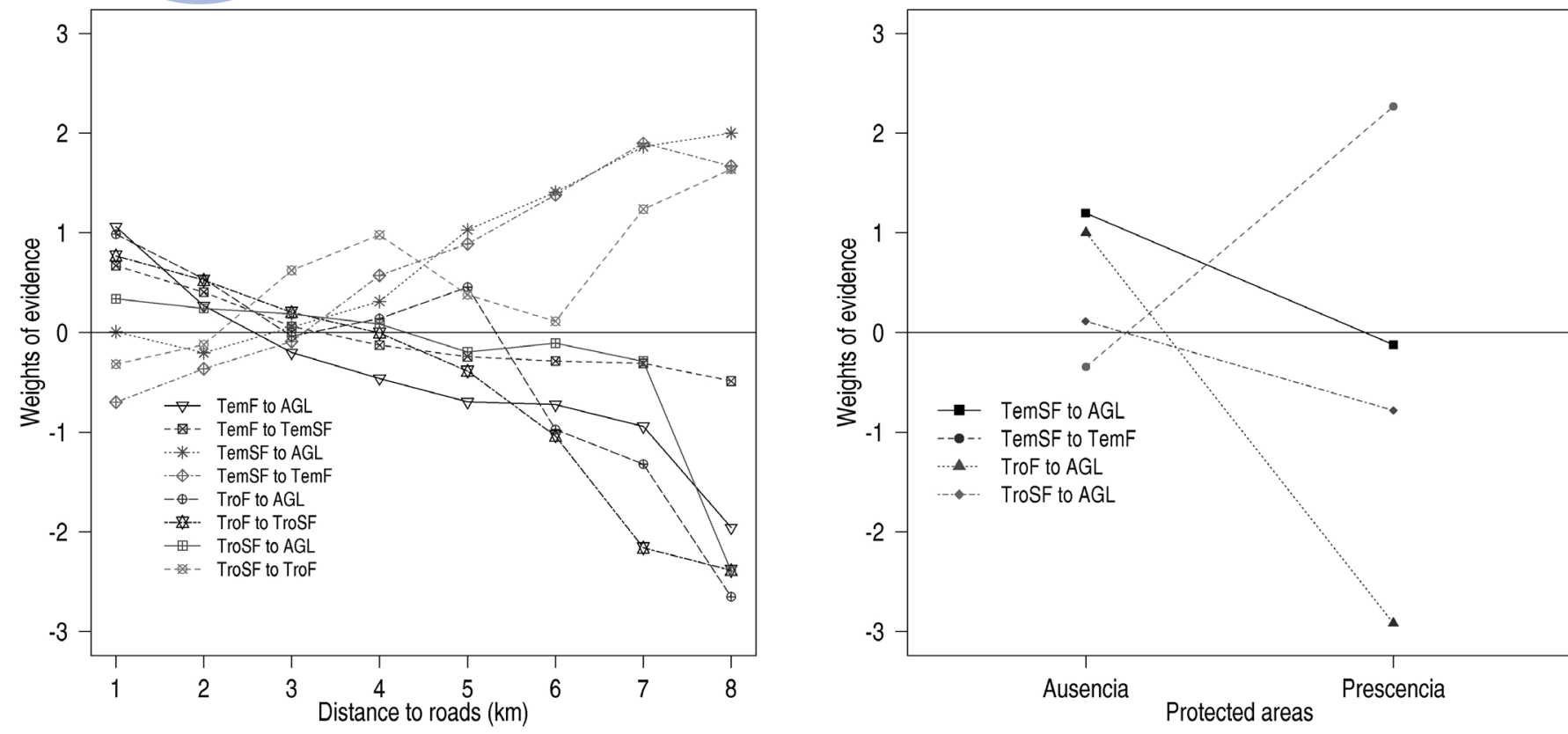

Figure 1s. Weights of evidence calculated for the variables: a) protected area presence and b) distance to roads, for specific transitions. TroF $=$ Closed tropical forests, TroSF $=$ Secondary tropical forests, TemF $=$ Closed temperate forests, TemSF $=$ Secondary temperate forests, $\mathrm{ALF}=$ Agriculture, livestock and forestry, $\mathrm{OC}=$ Other land cover. 
Figure 2s. Fuzzy similarity index between the real and simulated maps as a function of spatial resolution.

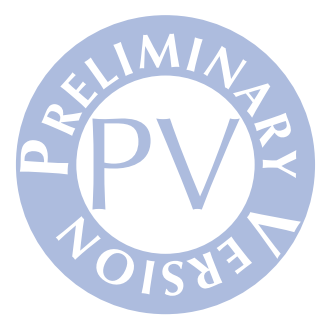

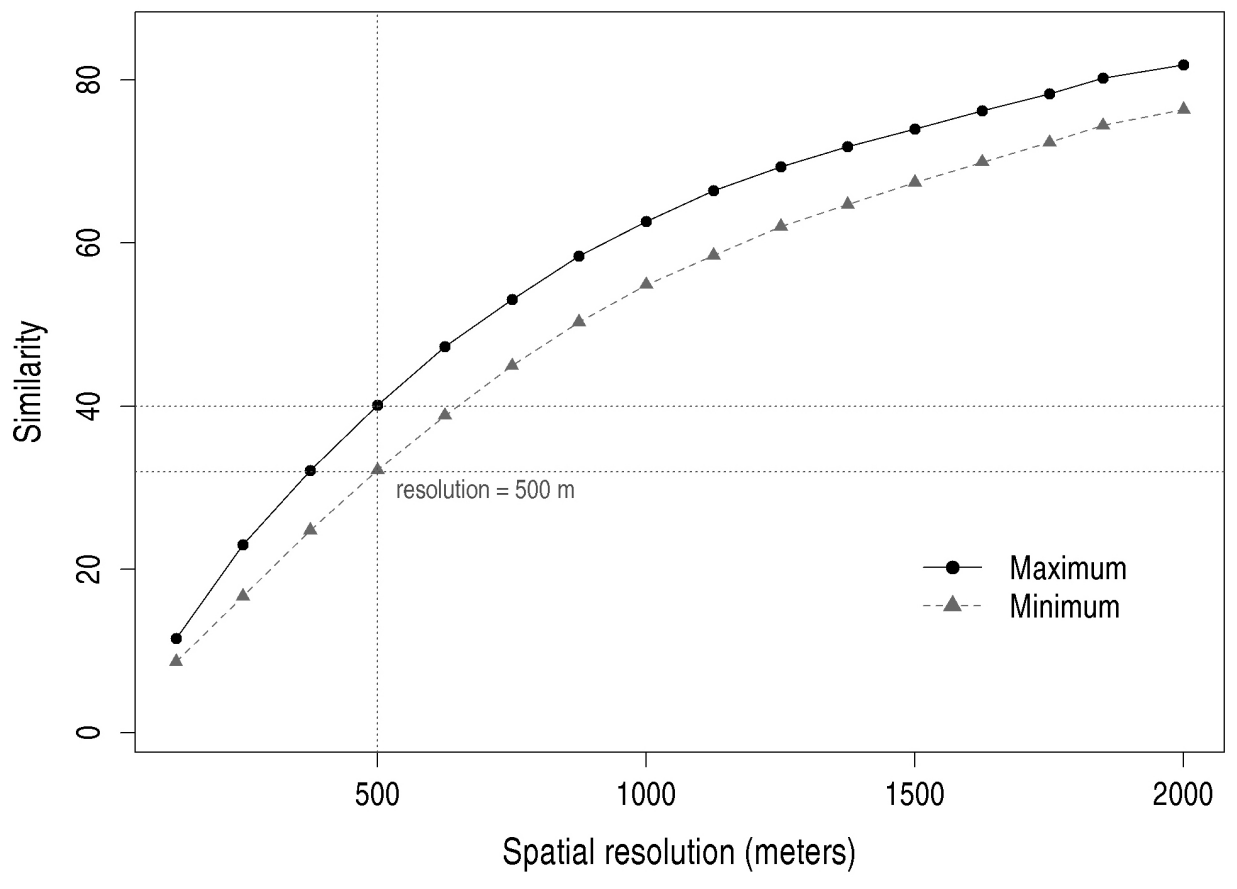

